\title{
Medical Publications: Walking a Thin Line
}

The growth in the volume of knowledge in human medicine, and especially in pulmonary medicine, is impressive. Diseases of the lung and airways are of major importance in terms of morbidity, mortality and cost [1]. Various groups have made forecasts for the global mortality development $[2,3]$. Four of the 10 most common causes of death fall within our area of expertise [4]. The importance of the various pneumological diseases for future health care can be induced from the size of the projected increase in lung diseases by 2050. These numbers are important, since they can give us some idea of what to expect in terms of future organizational, personnel and financial needs in the field of qualified pulmonary care.

For these reasons, the increase in research activity in this field is quite striking. When a keyword like 'pulmonary', 'lung' or 'chest medicine' or any word relating to a specific lung disorder is entered into scientific search machines such as PubMed, the number of cited literature shows a weekly increase that almost reaches the threedigit range. Currently, more than 750,000 papers are found when terms like these are entered.

After finishing medical school, everybody has the obligation to continue their education. In some countries, this notion is enshrined in law, but it is also a responsibility towards our patients. Ultimately, it is up to individuals to decide on how they wish to acquire new knowledge.

How can we monitor the flood of information? Furthermore, how can we guarantee the content and the quality of the information supplied? It is up to the editors, the associated editors, the reviewers as well as the publisher to work continuously on addressing problems of this kind.

Will it be easy to do this? I think it has not been easy in the past and it will become more complicated in the future. Let us have a look at the ranking system of the different journals. The impact factor is the measure that reflects the average number of citations to recent articles published in the journal. It is frequently used as a proxy for the relative importance of a journal within its field, with journals with higher impact factors being deemed to be more important than those with lower ones [5]. The impact factor of a journal is the average number of citations received per paper published in the journal during the 2 preceding years. In order to move up in the hierarchy, a journal needs an increase in the number of citations.

The easiest way is to encourage authors to include references from the journal in their current article. I believe every author has received such comments when revising an article. Hopefully, this will increase the scientific information in the article. The open question is where the limit for such self-citations is. On the other hand, the impact factor is an important issue for the author as well. Most of the research funding authorities also use the factor when determining the degree of refunding, a kind of money-back system. 
How to handle the problem of image editing is another issue that has to be addressed. If, for example, a radiological image where the author has utilized editing options such as contrast and brightness to highlight the important part of the picture is submitted, is this still the original figure or has it already been manipulated? To make it even more complicated: if the image of a patient has been altered, is this still the original figure or has it been manipulated?

Another unanswered question is plagiarism. Due to the rapidly growing number of journals and articles, nobody can oversee all publications, even within a small area. Therefore, it is possible that part of a manuscript may have been published before. But how many words or sentences or what percentage of an article must have been freshly written to call it a new publication? Is it 20 or $90 \%$, or something in between? If detected, how should the problem be handled? Should we work on the basis of a blacklist, on which we put the names of culprits, to inform other publishers? On the other hand, we also have to protect the authors. How many ideas have been stolen or copied by reviewers, for example, in the situation where someone is asked for a review of a paper with the same topic shortly prior to the submission of their own publication. How should situations like this be handled? Another yet unanswered issue relates to the open access policy. If authors are expected to pay when they submit an article, does this mean guaranteed publication? Or is the review process as independent as in non-open access journals?

In summary, there is a need for defining concepts. It is the responsibility of the publisher and the editors of the journals to define rules, not once and for all, but as work in progress. For Respiration I can guarantee this on behalf of all the reviewers, associated editors and the publisher. Felix J.F. Herth, Heidelberg

\section{References}

1 http://www.who.int/whosis/whostat/2011/en/index.html.

2 http://www.erswhitebook.org/chapters/the-burden-of-lung-disease/.

3 http://epp.eurostat.ec.europa.eu/portal/page/portal/statistics/search database.

4 Horton R: GBD 2010: understanding disease, injury, and risk. Lancet 2012;380:2053-2054

5 http://en.wikipedia.org/wiki/Impact_factor. 